\title{
Modelling blast loads in rail vehicles
}

\author{
T. Anthistle \& D. I. Fletcher \\ Department of Mechanical Engineering, University of Sheffield, UK
}

\begin{abstract}
The open, accessible and crowded nature of urban mass transit networks has attracted previous attacks in London, Madrid and other cities, and it is very difficult to prevent an attacker entering while retaining normal operation of the system. The research presented here contributes to the modelling capability needed to apply a 'passive safety' approach in vehicle design, whereby the impact and consequences of a blast in a mass transit vehicle could be reduced.

The multi-material Arbitrary Lagrangian Eulerian (mm-ALE) approach with Fluid Structure Interaction (FSI) is widely reported in the literature, but has been seen as requiring to fine a mesh to be applicable to large scale structures. Reductions in computing cost and improvements in the speed of finite element codes allows large ALE models to be solved, and mm-ALE approach is shown to be effective at predicting the effects of explosions. Also studied is the recently implemented 2D to 3D mapping function available in LS-Dyna, and comparisons are made with the standard 3D approach in terms of computational expense and solution accuracy.
\end{abstract}

Keywords: ALE, FSI, finite element method, internal explosions, rail vehicles.

\section{Nomenclature}

$\begin{array}{llll}p & \text { Pressure } & V & \text { Volume } \\ E & \text { Internal energy } & \mu & \text { Volumetric parameter, } \frac{1}{V}-1 \\ D & \text { Damage paramter } & T^{* m} & \text { Homologous temperature } \\ \bar{\epsilon}^{p} & \text { Effective plastic strain } & \dot{\epsilon}^{*} & \text { Normalised strain rate }\end{array}$




\section{Introduction}

In recent years rail infrastructure across the world has been subject to terrorist attacks which have often taken the form of deliberate explosions. The most notable of these events, those that created the most casualties and displayed some planning, happened in London in July 2005 [1] and Madrid in 2004 [2], but significant events have occurred recently in both Russia [3] and India [4]. Understanding the consequences of a blast event on both the rail vehicle and its occupants is important if the impact of a potential future attack is to be reduced.

Rail infrastructure has not been the most prevalent site of terrorist attacks, but a 2005 report by RAND's Centre for Terrorism and Risk management policy [5] suggests a move towards 'soft civilian-centric venues' such as hotels, bars and restaurants and transportation systems. A report for the US Congress [6] also suggests that emerging trends, towards which security policy should be focused, include targets leading to high economic impact such as transportation infrastructure and tourism. When rail systems are attacked, bombings are seen to be the most frequent type of attacks, accounting for about $90 \%$ of attacks [7]. There is also a suggested correlation between number of casualties and economic impact, which could potentially explain the relatively high number of casualties seen in attacks such as London and Madrid, if compared with attacks carried out by the IRA in the UK in early 1990s [7], whose tactics were radically different from those being used by many current extremist terrorists.

The nature of mass transit systems means that perimeter security measures such as those seen in airports are unworkable, which significantly reduces the likelihood of an explosive device being detected before it makes it into the system. It is therefore important to be able to predict the likely effects on vehicles and their occupants, and to predict the effects that design modification may have on the mitigation of the risk due to explosions.

Blast loading of a variety of structures and materials has been well documented in the literature, in both experimental and numerical modelling forms. Much of this work to date has looked at simple planar structures exposed to air blasts, such as Rolled Homogeneous Armour [8], sandwich and metal foam panels [9$11]$ and glazing $[12,13]$, but there is also an increasing number of works looking at underwater explosions [14,15], and complex and large scale structures $[16,17]$. So far, the majority of this work has looked at designing structures and materials to resist the effects of explosions, but not so much published work exists on the likely effect of blasts on current structures which could be under threat, outside anecdotal evidence from terrorist attacks or accidental explosions.

Work as part of the EU project, RAILPROTECT, has sought to remedy this in relation to rail vehicles and their supporting infrastructure. Larcher et al. have published widely [18-20] on this topic using work undertaken using a specialised finite element code, designed specifically for looking at Fluid Structure Interaction (FSI). This work has identified the effects due to a variety of charge weights, internal configuration and two contrasting vehicle construction methods, and identified the risk of human death and eardrum rupture. 
The work reported here looks to explore the methods that can be used to simplify and speed up this type of analysis when purpose built software is not available, while ensuring that results are not degraded. Ultimately, the techniques discussed will be used to identify possible designs of rail vehicles that can be used to reduce the risk blast events pose to passengers.

\section{Modelling approach}

The modelling approach utilises the explicit finite element code LS-Dyna, which has built in functions for modelling the effect of blast loads on structures. These include methods which apply a simple free air explosive pressure time history to structures, as well a coupled fluid/structural calculation which models the detonation and explosive and the subsequent propagation of a blast wave through a fluid medium, the resulting structural deformation and the interaction. This coupled fluid/structural method is utilised here where there is a need to measure pressures that result from structural interactions throughout a rail vehicle.

\subsection{Structural models}

\subsubsection{Sidewall panel geometry}

Modern passenger rail vehicles are almost all of monocoque construction, most commonly from large sections of aluminium extrusion joined together with either welds or permanent mechanical fasteners. The side wall extrusions consist of two faces connected by diagonal webs. The thickness of the front and rear faces and the distance between webs varies considerably over the cross section of the vehicle, depending on the mechanical properties required at various points.

To understand parameters required to represent the above with a simplified model, a section of a rail vehicle side wall is modelled and subjected to a blast load. Two physical models of panels have been investigated, a single shell model, model A, and a more realistic model (see Figure 1) representative of the extrusions used in a rail vehicle construction, model B.

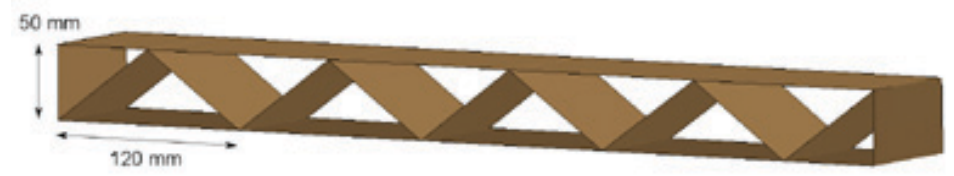

Figure 1: Extruded panel. 


\subsubsection{Simplified rail vehicle}

A simplified, single shell model of rail vehicle was built, based on the geometry of a British Rail Class 165 vehicle. This vehicle was chosen due to the availability of geometry and existing models, which were used in a previous study [21], and there is no suggestion that this vehicle is particularly at risk. This model was used to identify the important features of rail vehicles that should be modelled in order to accurately resolve pressure throughout a rail vehicle, without incurring unnecessary computational expense. A cross section of the vehicle, showing the geometry of the body shell and the location of pressure sensors in the ALE domain is shown in Figure 2.

The vehicle structure is modelled using 24,717 Belytschko-Tsay shell elements, and the ALE air domain consists of 1,238,208 1 point ALE multi-material solid elements. The model utilises quarter symmetry and appropriate symmetry boundary conditions are applied to the free edges of both the structural model and the ALE domain. The outer boundaries of the ALE domain are specified as nonreflecting to approximate the infinite nature of the air as it is clearly not possible to model an infinite air domain. The section of the rail vehicle modelled is $4 \mathrm{~m}$ long, $2.7 \mathrm{~m}$ high and $1.4 \mathrm{~m}$ wide at extremities. The ALE domain is $5 \mathrm{~m}$ long, $3.4 \mathrm{~m}$ high and $1.9 \mathrm{~m}$ wide.

\subsection{Structural material models}

Two structural material models are used throughout this work, simple plasticity model for steel, ${ }^{*}$ MAT_PLASTIC_KINEMATIC in LS-Dyna, with no rate dependency, and a the Johnson-Cook model for 6005-T6 aluminium [22], which is rate dependent and more suitable for high strain rate application. Typically, modern passenger rail vehicles built using extruded section are made from grades of aluminium similar to this. The non rate dependant steel model is used to allow comparisons between behaviour of different materials and material models. A rigid model is also implemented using an input keyword which turns all deformable parts into rigid parts.

Parameters for both of these models can be found in Table 1. The Johnson-Cook model calculates the flow stress at any point in time as [23]:

$$
\sigma_{y}=\left(A+B \bar{\epsilon}^{p^{n}}\right)\left(1+c \ln \dot{\epsilon}^{*}\right)\left(1-T^{* m}\right)
$$

where $A, B, c, n$ and $m$ are input parameters. The fracture strain is given by [23]:

$$
\epsilon^{f}=\left(D 1+D 2 e^{D 3 \sigma^{*}}\right)\left(1+D 4 \ln \dot{\epsilon}^{*}\right)\left(1+D 5 T^{*}\right)
$$

where $D_{1 \ldots .}$ are experimentally derived parameters. Element failure in this model occurs when $D$ reaches the value of 1 :

$$
D=\sum \frac{\Delta \bar{\epsilon}^{p}}{\epsilon^{f}}
$$


Table 1: Material model parameters.

\begin{tabular}{c||cccccc}
\hline Parameter & $\mathrm{E}$ & $\rho\left({ }^{\mathrm{kg}} / \mathrm{m}^{3}\right)$ & $\nu$ & $\sigma_{y}(\mathrm{MPa})$ & $\epsilon_{f}$ & $\mathrm{~A}(\mathrm{MPa})$ \\
\hline Steel & 207 & 7500 & 0.3 & 300 & 0.3 & - \\
$\mathrm{Al}$ & 70 & 2700 & 0.3 & - & - & 270 \\
\hline Parameter & $\mathrm{B}(\mathrm{MPa})$ & $\mathrm{n}$ & $\mathrm{C}$ & $\mathrm{m}$ & $\epsilon_{0}\left(\mathrm{~s}^{-} 1\right)$ & $\mathrm{c}_{p}(\mathrm{~kJ} / \mathrm{kg} / \mathrm{K})$ \\
\hline Steel & - & - & - & - & - & - \\
$\mathrm{Al}$ & 134 & 0.514 & 0.008 & 0.703 & 0.001 & 910 \\
\hline Parameter & $\mathrm{D}_{1}$ & $\mathrm{D}_{2}$ & $\mathrm{D}_{3}$ & $\mathrm{D}_{4}$ & $\mathrm{D}_{5}$ & \\
\hline Steel & - & - & - & & & \\
$\mathrm{Al}$ & 0.060 & 0.497 & -1.551 & 0.029 & 6.800 & \\
\hline Parameter & $\mathrm{T}_{m}(\mathrm{~K})$ & $\mathrm{T}_{r}(\mathrm{~K})$ & & & & \\
\hline Steel & - & - & & & \\
$\mathrm{Al}$ & 893 & 293 & & &
\end{tabular}

\subsection{ALE model}

The ALE approach with FSI has been applied widely in recent years to model explosions in situations where empirical methods are unable to predict blast pressure and structural response. The ALE/FSI method requires the use of solid ALE mesh of both the charge and air to model the detonation and the propagation of the blast wave throughout the domain under investigation. The Lagrangian structural model of interest is included within the ALE mesh and the solutions of the Lagrangian and ALE meshes are coupled using a penalty algorithm, which applies a penalty force to the ALE materials when they meet a structure to ensure they do not pass through the Lagrangian structure. It is this penalty force that causes the deformation of the structural model. The high explosive was modelled using the *HIGH_EXPLOSIVE material model and the Jones-WilkinsLee equation of state (4) [23], and air is modelled using the *NULL material model and linear polynomial equation of state (5) [23]. The parameters $A, B, R_{1,2}, \omega$ and $C_{1 \ldots 6}$ are material constants.

$$
\begin{gathered}
p=A\left(1-\frac{\omega}{R_{1} V}\right) e^{-R_{1} V}+B\left(1-\frac{\omega}{R_{2} V}\right) e^{-R_{2} V}+\frac{\omega E}{V} \\
p=C_{0}+C_{1} \mu+C_{2} \mu^{2}+C_{3} \mu^{3}+\left(C_{4}+C_{5} \mu+C_{6} \mu^{2}\right) E
\end{gathered}
$$

The ALE model described here utilises both a full $3 \mathrm{D}$ method as well as a mapped 2D to 3D method. In the full 3D method, a physical solid model of the explosive charge is meshed into the solid model that represents the air domain and the shock wave propagates from the solid explosive model into the air domain. 
This is how coupled explosive/structural models have conventionally been set up, but in recent years a 2D to 3D mapping function has allowed the solution to be broken up into stages to reduce computational cost.

In the $2 \mathrm{D}$ to $3 \mathrm{D}$ model, a $2 \mathrm{D}$ model of the charge and air is created and this is used to model the detonation and initial propagation of pressures and explosive products into the air domain. This solution is then mapped onto the full 3D domain based on symmetry in the blast before any structural interaction occurs, removing the need to model the detonation in $3 \mathrm{D}$ - a computationally intense and critical phase which is removed as the $3 \mathrm{D}$ solutions begins at the time the $2 \mathrm{D}$ solution ends.

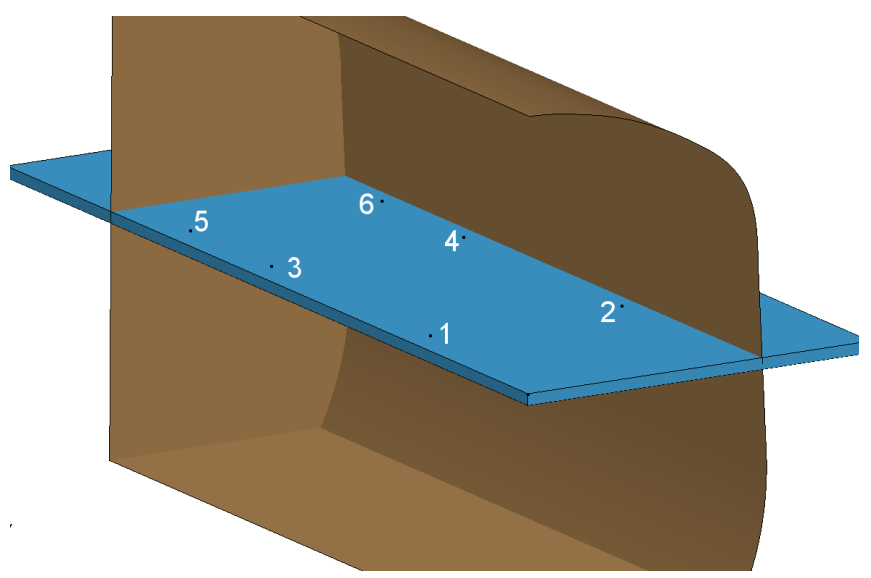

Figure 2: Locations of pressure sensors within a rail vehicle section.

\subsection{Verification, validation and model accuracy}

The cost of conducting a full scale trial has prevented validation of the models described here against a full vehicle test. An alternative route to validation has been pursued through experimental data available in the literature and from universally used blast prediction methods, such as ConWep [24]. Within the project team at Sheffield, Abbott [25] has demonstrated that the code used in the current research generates side-on over-pressures that differed by only $1.3 \%$ from experimental results. Preliminary work leading up to this result showed pressure impulses were within $15 \%$ of the values from ConWep. To build on this literature data based modelling validation future work is planned to conduct an experiments using scaled tests and high explosives. These will be used to further validate the modelling by gathering pressures data from explosions within structures with complex internal geometry. 


\section{Results and discussion - side wall panel}

The simplified and extruded panels, models A and B, were subjected to a blast load from a large spherical charge of TNT, detonated $1.32 \mathrm{~m}$ from the panel under investigation, which is the distance from the centreline to the outside wall of a Class 165 rail vehicle. The model is symmetrical along the centre of the panel, and is modelled as clamped around the edge in all degrees of freedom.

To investigate the differences in the two structural models, deflection and pressure histories are recorded from several versions of model A using a range of thickness values for the elements, and compared with model B.

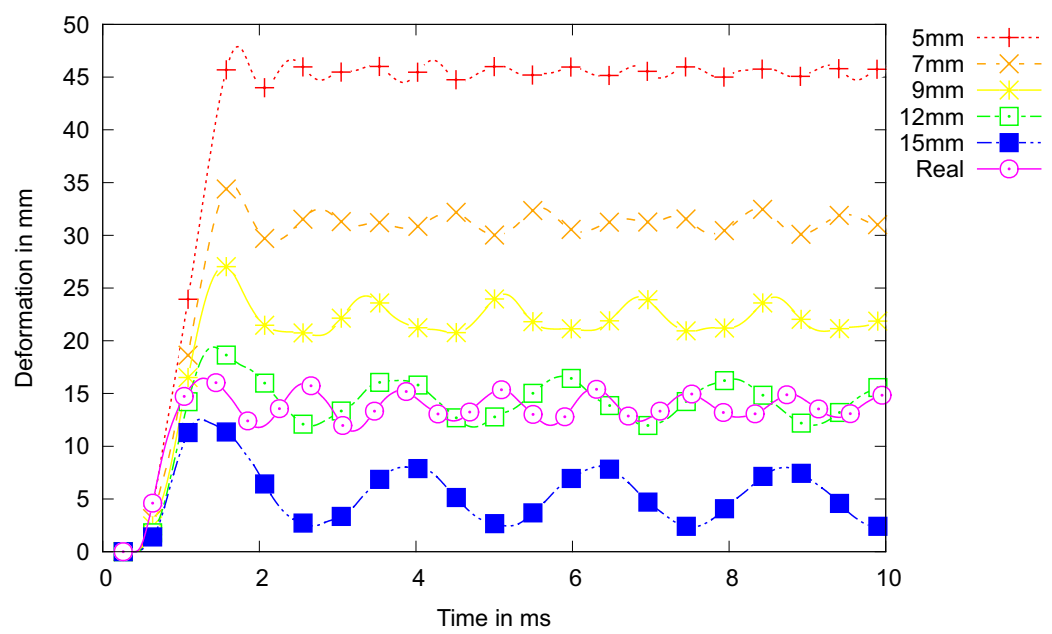

Figure 3: Structural deformation of various panels at centre

Figure 3 shows the deformation histories at the centre of several panels, with the increasing thickness showing reduced peak plastic deformation as expected. The real layered panel shows a deformation history that is similar to a single shell panel of $12 \mathrm{~mm}$ thickness, but with a reduced maximum deflection of $16.4 \mathrm{~mm}$ compared to $19.4 \mathrm{~mm}$. The real panel also displays a higher natural frequency and greater damping than a single shell model. The results indicate that careful choice of panel thickness for model A can represent the peak static deformation, but cannot accurately represent the transient deformation history.

\section{Vehicle models}

\subsection{Mapped versus full 3D}

A mapped 2D to 3D method is used to compute through vehicle pressures and structural deformations, and comparisons made at various points throughout the 
vehicle, which again utilises a quarter symmetry representation of a rail vehicle. Figure 4.1 shows the pressure history at a point in the corner of the rail vehicle section, shown as the pressure sensor 6 in Figure 2. This serves as a good point to compare pressures, as a large amount of reflections and superposition occurs here due to wave interaction with the structure, which leads to a complex pressure response with a large number of sharp jumps in pressure. The full and mapped model show close correlation, with pressure curves showing similar peaks at similar times. The total impulse, shown in Table 2, at this point also shows close correlation between the two modelling approaches. If a numerical integration is performed over the full $25 \mathrm{~ms}$ simulation (0-20ms shown in Figure 4.1 for clarity), the total impulse difference between the two models is just $4.2 \%$, reinforcing the close correlation shown in Figure 4.1.

Deformation history for the two models, taken at the point in the rail vehicle closest to the charge (where the deformation is greatest) is shown in Figure 4.1. Full 3D and mapped models show almost identical behaviour, with little noticeable difference in structural behaviour.

Table 2: Impulses for full and mapped models.

\begin{tabular}{c||cc}
\hline Model & Full 3D & Mapped 3D \\
\hline$I$ (kPa-ms) & 4345 & 4532 \\
\hline
\end{tabular}

\subsection{Influence of material model}

The influence of variations in material modelling on predictions structural deformation is important, as complex material models which are vital to achieve an accurate response in numerical modelling, lead to significant increases in computational time when applied unnecessarily. Here, a comparison is made between a rigid, simple plasticity and a strain rate dependent structural material model, which are described earlier.

Figure 5 shows pressures at sensors 3 and 6 (see Figure 5(b)). Both plots shows that during the initial propagation of the wave, to approximately $5 \mathrm{~ms}$ at both points, that the pressure response is almost identical for each material model. Beyond this, reductions in peak pressures for the simple plasticity model and rate dependant aluminium failure model are seen, with Figure 5(a) showing particularly strong differences in the pressure at $13 \mathrm{~ms}$ between the 3 material models.

The corresponding impulses for each material model, calculated from pressure plots 5(a) and 5(b), $I_{3}$ and $I_{6}$ respectively, can be found in Table 3. As well as peak overpressure, impulses are very important in assessing the potential injury that a blast wave could cause, and significant differences in impulse are seen between the three material models. The impulse seen at both sensor 3 and 6 is roughly 


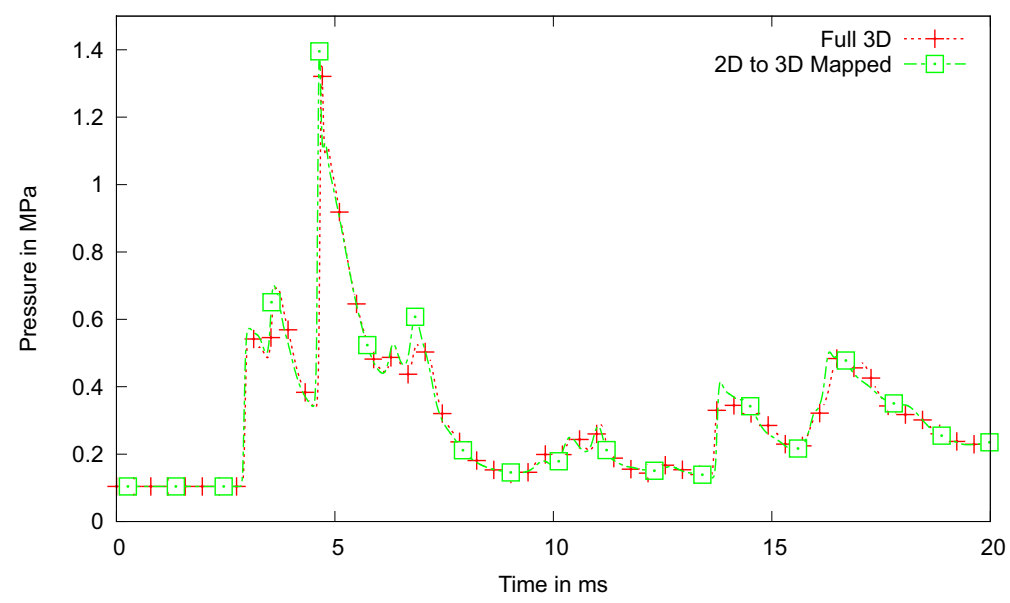

(a) Pressure at history at corner of vehicle, shown as sensor 6 in Fig. 2

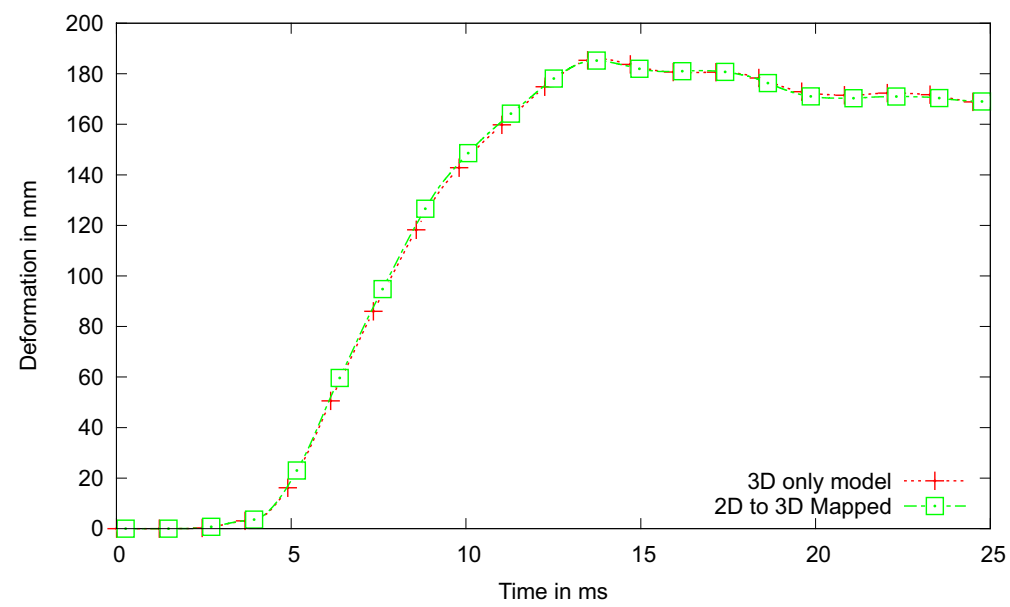

(b) Deformation at point of vehicle structure closest to charge

Figure 4: Pressure and deformation plots comparing the full and 3d mapped model.

$20 \%$ lower (19.2\% and $17.7 \%$ respectively) in the plasticity model and $30 \%$ lower (29.8\% and $28.9 \%$ respectively) in the failure model compared to the rigid model.

The causes for the differences in pressure and impulse between these models are a combination of both the inertial response of the structure and total deformation. The initial peaks, up to $10 \mathrm{~ms}$, where models show similarity in both the value 


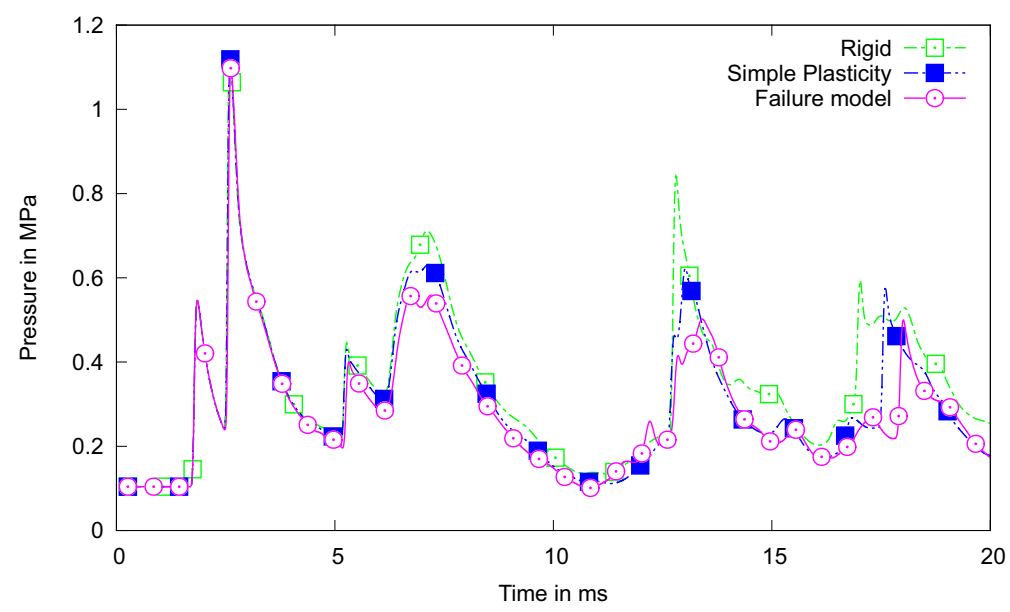

(a) Pressure at sensor 3 (see Fig. 2)

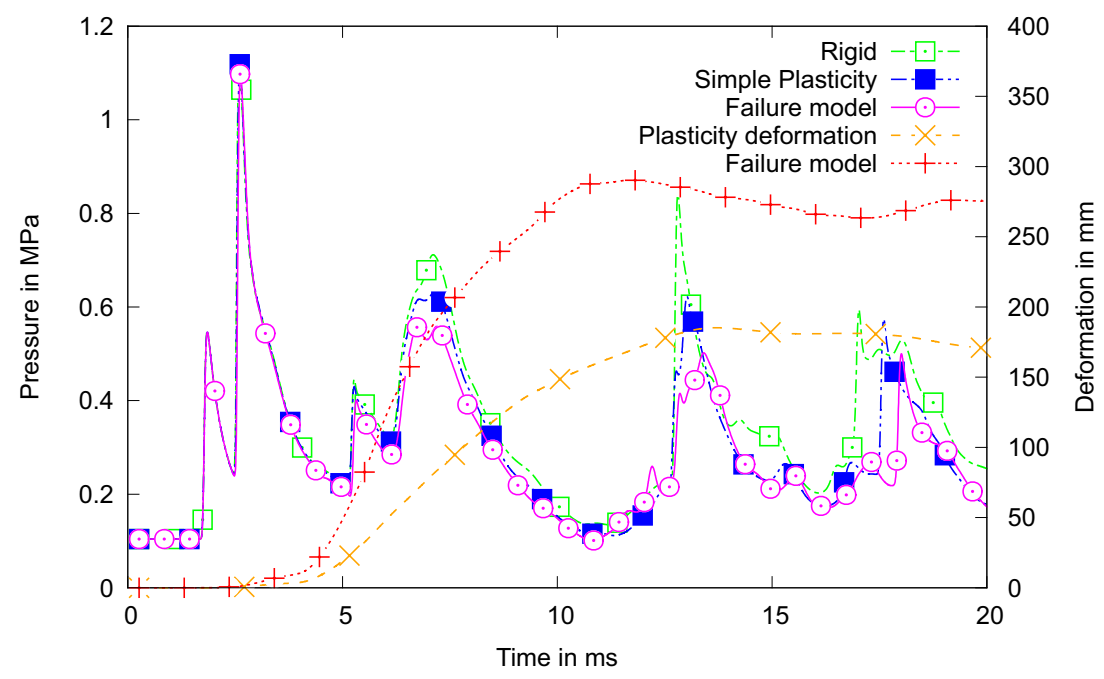

(b) Pressure at sensor 6 (see Fig. 2)

Figure 5: Pressure plots resulting from different structural material models.

pressure and arrival time of the wave, occur as the structural deformation plays no part in the response - the wave has been reflected and moved from the internal surface of the vehicle before any significant movement of that surface takes place, 
Table 3: Impulses for various material models.

\begin{tabular}{c||ccc}
\hline Model & Rigid & Steel - Plasticity & Al - Rate Dependant \\
\hline$I_{3}(\mathrm{kPa}-\mathrm{ms})$ & 5467 & 4509 & 4045 \\
$I_{6}(\mathrm{kPa}-\mathrm{ms})$ & 5397 & 4521 & 4032 \\
\hline
\end{tabular}

as seen in Figure 5(b). The rate and extent to which the structure deforms will then effect subsequent reflections from the surface, both in terms of magnitude and time - if the structure is more highly deformed, the incoming wave will have to travel further before it is reflected, and will have dissipated more energy before being reflected, reducing the magnitude of the reflected wave.

\section{Conclusions and future work}

Structural deformations, pressure and impulses have been calculated throughout a simplified rail vehicle model, as part of ongoing research to use numerical modelling methods to identify potential passive safety measures to mitigate the effects of blast loads on rail vehicles and passengers. Three areas of possible simplification have been investigated here; detailed versus simplified body structure, simple versus complex material models and full $3 \mathrm{D}$ versus $2 \mathrm{D}$ to $3 \mathrm{D}$ mapped ALE solutions.

Vehicle panel investigations using model A and model B have shown that despite careful choice of element thickness to ensure model A behaves in a similar way to model $\mathrm{B}$, the response of model $\mathrm{A}$ is quite different to model $\mathrm{B}$ in terms of structural deformation. This could potentially be very significant on the scale of a rail vehicle and a vehicle structure similar in cross section to model B will need to implemented in the model, if correct predictions on structural deformations are to be made.

A simplified structural model of a rail vehicle has been investigated using a single shell approach and 3 different material models. The difference in structural response of the vehicle body has been shown to affect the pressures and impulses calculated through the vehicle, with the strain rate dependent failure model for aluminium showing the most deformation. As a result the reflected pressures are lower than predicted for the less realistic rigid material model.

The 2D to 3D ALE mapping method is shown to produce results comparable to a full 3D simulation, but with significant time/cost saving, which will allow increasingly complex models to be run without incurring unnecessary computational expense, as well as reducing the time required to set up and create meshes for models.

Accurate prediction of complete pressure histories and impulses will only be possible with a more comprehensive vehicle model which is better able to predict structural deformation. This will need to include a structural model similar to that used in model B of the panel investigation, and the rate dependant material model 
used for the full rail vehicle. Despite this, even with the current simplified models it is possible to predict the first peak in pressure from an explosion, where structural deformation has not begun, and thus plays no significant part in the reflection of pressure waves.

Future work will focus on use of a more comprehensive vehicle model in order to ensure predictions of realistic deformations and accurate calculation of critical pressures and impulses that affect passengers. This will include internal features, whose size and position could optimized within guidelines to reduce pressures and impulses experienced by some passengers, as well as how variations in overall vehicle construction, such as through carriage designs, alter the risk of explosions to passengers.

\section{References}

[1] BBC News, BBC News | Special Reports | London Explosions. http://news.bbc.co.uk/l/hi/in_depth/uk/2005/london_explosions/default.stm, 2009.

[2] BBC News, BBC News | Special Reports | 2004 | Madrid train attacks. http://news.bbc.co.uk/1/hi/in_depth/europe/2004/madrid_train_attacks/ default.stm, 2009.

[3] BBC News, BBC News | Moscow Metro hit by deadly suicide bombings. http://news.bbc.co.uk/1/hi/8592190.stm, 2010.

[4] BBC News, BBC News | In Depth | 2004 | Mumbai train attacks. http://news.bbc.co.uk/1/hi/in_depth/south_asia/2006/mumbai_train_attacks/ default.stm, 2003.

[5] Chalk, P., Hoffman, B., Reville, R. \& Kasupski, A., Trends in terrorism. Rand Corporation, 2005.

[6] Perl, R., Trends in terrorism. DTIC Document, 2006.

[7] Powell, J. \& Fletcher, D.I., The need for developing an effective and acceptable engineering response to terrorist attacks on railway systems. Proceedings of the Institution of Mechanical Engineers, Part F: Journal of Rail and Rapid Transit, 225(4), pp. 359-371, 2011.

[8] Chafi, M., Karami, G. \& Ziejewski, M., Numerical analysis of blastinduced wave propagation using FSI and ALE multi-material formulations. International Journal of Impact Engineering, 36(10-11), pp. 1269-1275, 2009.

[9] Karagiozova, D., Nurick, G. \& Langdon, G., Behaviour of sandwich panels subject to intense air blasts-Part 2: Numerical simulation. Composite Structures, 91(4), pp. 442-450, 2009.

[10] Zhu, F., Zhao, L., Lu, G. \& Gad, E., A numerical simulation of the blast impact of square metallic sandwich panels. International Journal of Impact Engineering, 36(5), pp. 687-699, 2009.

[11] Hanssen, A., Enstock, L. \& Langseth, M., Close-range blast loading of aluminium foam panels. International Journal of Impact Engineering, 27(6), pp. 593-618, 2002. 
[12] Chung, J., Consolazio, G., Dinan, R. \& Rinehart, S., Finite-Element Analysis of Fluid-Structure Interaction in a Blast-Resistant Window System. Journal of Structural Engineering, 136, p. 297, 2010.

[13] Wei, J. \& Dharani, L., Response of laminated architectural glazing subjected to blast loading. International journal of impact engineering, 32(12), pp. 2032-2047, 2006.

[14] Kim, J.H. \& Shin, H.C., Application of the ale technique for underwater explosion analysis of a submarine liquefied oxygen tank. Ocean Engineering, 35(8-9), pp. 812-822, 2008.

[15] Vulitsky, M. \& Karni, Z., Ship Structures subject to high explosive detonation. 7th International LS-DYNA Users Conference, 2002.

[16] Grujicic, M., Arakere, G., Nallagatla, H., Bell, W. \& Haque, I., Computational investigation of blast survivability and off-road performance of an uparmoured high-mobility multi-purpose wheeled vehicle. Proceedings of the Institution of Mechanical Engineers, Part D: Journal of Automobile Engineering, 223(3), pp. 301-325, 2009.

[17] Børvik, T., Hanssen, A., Dey, S., Langberg, H. \& Langseth, M., On the ballistic and blast load response of a $20 \mathrm{ft}$ ISO container protected with aluminium panels filled with a local mass-Phase I: Design of protective system. Engineering Structures, 30(6), pp. 1605-1620, 2008.

[18] Larcher, M., Casadei, F., Giannopoulos, G., Solomos, G., Planchet, J. et al., Determination of the risk due to explosions in railway systems. Proceedings of the Institution of Mechanical Engineers, Part F: Journal of Rail and Rapid Transit, 225(4), p. 373, 2011.

[19] Larcher, M., Casadei, F. \& Solomos, G., Influence of venting areas on the air blast pressure inside tubular structures like railway carriages. Journal of Hazardous Materials, 2010.

[20] Larcher, M., Casadei, F. \& Solomos, G., Risk analysis of explosions in trains by fluid-structure calculations. Journal of Transportation Security, 3(1), pp. 57-71, 2010.

[21] Kotsikos, G., Robinson, M., Zangani, D. \& Roberts, J., Investigation of the weld unzipping failure mode during collisions of welded aluminium rail vehicles. Proceedings of the Institution of Mechanical Engineers, Part F: Journal of Rail and Rapid Transit, 222(1), p. 59, 2008.

[22] Børvik, T., Clausen, A., Eriksson, M., Berstad, T., Sture Hopperstad, O. \& Langseth, M., Experimental and numerical study on the perforation of aa6005-t6 panels. International Journal of Impact Engineering, 32(1-4), pp. 35-64, 2005.

[23] Livermore Software Technology Corporation (LSTC), LS-DYNA Keyword User's Manual Version 971. Volume 2: Material Models, pp. 1385-2206, 2003.

[24] Hyde, D., CONWEP, Conventional Weapons Effects Program. US Army Engineer Waterways Experiment Station, Vicksburg, MS, 1992.

[25] Abbott, C., The Effect of Blast Loads on Rail Vehicle Bodies. MEng Thesis, University of Sheffield, 2011. 